\title{
Treatment of Acute Venous Thromboses and Pulmonary Embolism during Pregnancy
}

\author{
Mikhail M. Vinokurov, $\mathrm{PhD}, \mathrm{ScD}^{1^{*}}$; Anton A. Yakovlev, $\mathrm{PhD}^{2}$; Vasily P. Ignatiev'; \\ Natalia I. Douglas, $\mathrm{PhD}, \mathrm{ScD}^{1}$; Gennady A. Palshin, $\mathrm{PhD}, \mathrm{ScD}^{1}$; \\ Iana G. Rad, $\mathrm{PhD}^{1}$; Innokenty D. Ushnitsky, $\mathrm{PhD}, \mathrm{ScD}^{1}$ \\ ${ }^{1}$ M. K. Ammosov North-Eastern Federal University \\ ${ }^{2}$ Republican Hospital No. 2-Center for Emergency Medical Care \\ Yakutsk, the Republic of Sakha (Yakutia), Russia
}

\begin{abstract}
The aim of the study was to improve the results of the treatment of acute ascending varicothrombosis, deep vein thrombosis (DVT) and pulmonary embolism (PE) during pregnancy and the postpartum period. The study included 22 pregnant women aged between 20 and 41 years in different periods of pregnancy and in the early postpartum period, with acute thrombosis of deep and superficial veins of the lower extremities complicated by PE. All of the generally accepted methods for treatment of DVT, varicothrombophlebitis and PE were applied. In 16(72.8\%) pregnant women with DVT of the lower limbs, in the absence of freefloating thrombus, conservative treatment was effective; an IVC filter was placed in only 1 patient. Combined phlebectomies of GSF with thrombosed tributaries were performed in 4(18.8\%) patients with ascending varicothrombosis in the early postpartum period, resulting in early recovery and discharge from the hospital. Thrombolytic therapy in the patient with massive PE in the first trimester of pregnancy saved the life of the mother and child. (International Journal of Biomedicine. 2018;8(3):244-246.)
\end{abstract}

Key Words: pulmonary embolism • deep vein thrombosis • pregnancy • low molecular weight heparin

\section{Abbreviations}

DVT, deep vein thrombosis; GSV, great saphenous vein; FFT, free-floating thrombus; IVC, inferior vena cava; LMWH, low molecular weight heparin; VTE, venous thromboembolism; PE, pulmonary embolism; USDS, ultrasonic duplex scanning.

\section{Introduction}

In regions without specialized vascular hospitals, patients with phlebotrombosis are hospitalized in emergency general surgical hospitals, as patients with an acute condition that threatens their lives. ${ }^{(1-3)}$ In general hospitals, the solution of tactics for diagnostic and treatment has a number of peculiarities: the standards of examination and treatment of patients with deep vein thrombosis (DVT) and its complications

*Corresponding author: Prof. Mikhail M. Vinokurov, MD, PhD, ScD. M. K. Ammosov North-Eastern Federal University. Yakutsk, the Sakha Republic, Russia. E-mail: mmv_mi@rambler.ru are not always observed. In addition, there are no unified algorithms for choosing the optimal tactics depending on the level and nature of thrombotic veins. Unfortunately, the most important tactical decisions are often based on a subjective view of the patient's condition. ${ }^{(4-6)}$

Clinical diagnosis of pulmonary thromboembolism in pregnancy remains difficult because of pregnancy associated physiological symptoms and signs, which can mimic those of enous thromboembolism. ${ }^{(7)}$

The aim of the study was to improve the results of the treatment of acute ascending varicothrombosis, deep vein thrombosis and pulmonary embolism during pregnancy and the postpartum period. 


\section{Materials and Methods}

In 2016-2017, 22 pregnant women aged between 20 and 41 years in different periods of pregnancy and in the early postpartum period, with acute thrombosis of deep and superficial veins of the lower extremities complicated by $\mathrm{PE}$, were prospectively enrolled for surgical treatment at the Center for Emergency Medical Care. These women had been referred by the female consultations or departments of pathology at maternity hospitals. Superficial venous thromboses with ascending varicothrombosis with the threat of FFT were diagnosed in 4 women in the postpartum period. Thrombosis of the iliofemoral segment was diagnosed in 5 cases, of the femoropopliteal segment - in 6 cases, and of the popliteal segment - in 4. Acute ileofemoral thrombosis was complicated by massive $\mathrm{PE}$ in 1 patient in the first trimester of pregnancy and by non-massive $\mathrm{PE}$ in 1 patient in the third trimester of pregnancy.

The examination of patients at the pre-hospital stage included the collection of complaints and anamnesis, a physical examination, a laboratory blood test with the obligatory determination of clotting and bleeding time, ECG, amd chest X-ray. In patients with signs of PE, CT examination of the thoracic cavity was performed in vascular regimen, and X-ray imaging was performed by installing a catheter for targeted thrombolytic therapy. The main method of instrumental examination of all patients, both at a prehospital stage and during treatment, was USDS. In all cases, ultrasound diagnosis consisted of a series of successive stages: 1) Confirmation of the presence of DVT; 2) Determination of the localization and extension of DVT; 3) Determination of the nature of the thrombotic process - the presence of a FFT and its length; 4) Identification of the risk for PE development; 5) Determination of the massiveness of PE.

Patients with FFT underwent USDS monitoring daily for 5-7 days. ${ }^{(1,7,9,10)}$ Anticoagulants of a low molecular weight were used to treat pregnant women in accordance with the national clinical recommendation of the Russian Society of Surgeons. (RSS,2015). ${ }^{(4)}$ Sixteen patients received conservative treatment - LMWH (clexane, fraxiparine) in therapeutic doses, taking into account the weight of the patients, as well as DVT elastic compression stockings. ${ }^{(3-6)}$ During treatment, all patients underwent monitoring via the coagulogram and ultrasonic venous duplex examination. After reducing leg edema, the threat for FFT, and active recanalization of thrombosed veins, the patients were transferred to the Perinatal Center of the Republican Hospital No.1 (National Center of Medicine) for further dynamic observation and treatment, as well as for maintaining pregnancy.

Active surgical tactics were used for ascending varicothrombosis of superficial veins of GSV in the early postpartum period. Combined phlebectomies were performed in 4(18.8\%) patients. Patients were discharged 4-5 days after the operation. To prevent recurrent PE, at the beginning of the third trimester of pregnancy an inferior vena cava (IVC) filter was installed in a woman with non-massive PE, which was removed after the delivery.

Successful regional thrombolytic therapy was conducted for one patient with massive PE during the first trimester of pregnancy (development time of less than 24 hours). After thrombolytic therapy, a course of LMWH was administered according to body weight. An IVC filter was not installed. Subsequently, the patient was transferred to the Perinatal Center for further dynamic observation, treatment and maintenance of pregnancy. The patient continued to receive therapeutic anticoagulation during pregnancy. A Cesareanborn baby was full-term and healthy.

\section{Results}

In $16(72.8 \%)$ pregnant women with DVT of the lower limbs, in the absence of FFT, conservative treatment was effective; an IVC filter was placed in only 1 patient.

Combined phlebectomies of GSF with thrombosed tributaries were performed in 4(18.8\%) patients with ascending varicothrombosis in the early postpartum period, resulting in early recovery and discharge from the hospital.

Thrombolytic therapy in the patient with massive PE in the first trimester of pregnancy saved the life of the mother and child. Pregnancy successfully ended with operative delivery and the birth of a full-term, healthy child.

The presence of FFT (from $2 \mathrm{~cm}$ to $4 \mathrm{~cm}$ in length) is an indication for the installation of a temporary IVC filter in pregnant women.

\section{Conclusion}

- All of the generally accepted methods for treatment of DVT, varicothrombophlebitis and PE can be used in pregnancy and the early postpartum period. . $^{(1,3-6)}$

- The analysis of scientific literature and expert evaluation of the outcomes of pregnancy and childbirth complicated by DVT, varicothrombophlebitis and PE, as well as our own experience in the treatment of pregnant women, prove the importance of creating special algorithms for managing such patients, taking into account the diagnostic and technical capabilities of the hospital.

- Termination of pregnancy as an initial stage in the fight against PE is an erroneous tactic. Pregnancy is not the cause of the disease, but only a factor that aggravates a woman's condition. Targeted thrombolytic therapy in pregnant women with massive PE is strongly recommended.

- Surgical treatment of acute ascending varicothrombosis in the early postpartum period avoids and minimizes the risk of thromboembolic complications.

\section{Competing interests}

The authors declare that they have no competing interests.

\section{References}

1. Aleksandrov BD. Investigation of the hemostatic system and the rationale for antithrombotic therapy with fraxiparine in pregnant women with gestosis Abstract of PhD Thesis. 
Moscow; 2000. [In Russian].

2. Vardanyan AV, Badanyan AL, Mumladze RB, Patrushev LI, Rojtman EV, Dolidze DD, Tokarev KY. Idiopathic deep vein thrombosis: modern approaches to diagnosis and treatment. Flebologiya. 2014;8(2):16-20. [Article in Russian]. 3. Balovneva E.V,Avchenko M.T. Thrombosis as complication of pregnancy and labor. Prevention of thromboembolic complications. Studencheskii. 2017;5(5). Available from: https://sibac.info/journal/student/5/75816 [Article in Russian]. 4. Russian clinical recommendations "Diagnosis, treatment and prevention of venous thromboembolic complications". Edited by A.I. Kirienko. Moscow; 2015. [In Russian].

5. Prevention of venous thromboembolic complications in obstetrics and gynecology. Clinical recommendations. Akusherstvo I Ginekologiya. 2014;(10) (Suppl):1-18.[In Russian].

6. VTE, thrombophilia, antithrombotic therapy, and pregnancy: Antithrombotic Therapy and Prevention of Thrombosis, 9th ed: American College of Chest Physicians Evidence-Based Clinical Practice Guidelines. Chest.
2012;141(2 Suppl):e 691S-736S. doi: 10.1378/chest.11-2300. 7. Simcox LE1, Ormesher L2, Tower C1, Greer IA3. Pulmonary thrombo-embolism in pregnancy: diagnosis and management. Breathe (Sheff). 2015 Dec;11(4):282-9. doi: 10.1183/20734735.008815

8. Krylov AYu, Shulutko AM, Osmanov EG, Khmyrova SE, Gogokhiya TR, Lobanova MV. [Clinico-diagnostic algorithm in the treatment of patients with acute varicothrombophlebitis of the lower extremities]. Ross Med Zhrnal. 2010;(2):20-25. [Article in Russian].

9. Fokin AA, Prikhodko VV, Medvedev AP, Vladimirsky VV. Surgical prophylaxis and treatment of pulmonary embolism. Chelyabinsk; 2010. [In Russian].

10. Konstantinides SV, Torbicki A, Agnelli G, Danchin N, Fitzmaurice D, Galiè N, et al.; Task Force for the Diagnosis and Management of Acute Pulmonary Embolism of the European Society of Cardiology (ESC). 2014 ESC guidelines on the diagnosis and management of acute pulmonary embolism. Eur Heart J. 2014 Nov 14;35(43):3033-69, 3069a-3069k. doi: 10.1093/eurheartj/ehu283. 